\title{
The effect of alpha and beta adrenergic blocking drugs upon the aversive threshold of rats
}

\author{
VINCENT P. HOUSER and RANDALL J. CASH \\ Psychotropic Drug Laboratory, Veterans Administration Hospital, Perry Point, Maryland 21902
}

\begin{abstract}
An attempt was made to assay the analgesic potency of several adrenergic agents which included: reserpine $(.62,1.25,2.50 \mathrm{mg} / \mathrm{kg})$, phenoxybenzamine, an $\alpha$-adrenergic blocking agent $(5.0,10.0$, $20.0 \mathrm{mg} / \mathrm{kg}$ ), and propranolol, a $\beta$-adrenergic blocking agent $(1.0,2.0,3.0,4.0,6.0,8.0 \mathrm{mg} / \mathrm{kg})$ in the rat using the spatial preference technique. Only the $\beta$-adrenergic blocking agent, propranolol, consistently elevated the aversive threshold over a wide range of doses without affecting motor activity. Reserpine augmented the aversive threshold only under the highest dose tested, while phenoxybenzamine produced no reliable effects on pain sensitivity. These results were interpreted to suggest that the high dose of reserpine may have elevated the aversive threshold indirectly through its toxic effects on motor activity. Propranolol, on the other hand, may have produced a mild analgesia through the drug's local anesthetic properties. It was suggested that reductions in central adrenergic tone via the administration of high doses of various drugs may elevate the aversive threshold indirectly by producing debilitating motor deficits.
\end{abstract}

Earlier reports from this laboratory have indicated that manipulation of adrenergic tone can lead to changes in pain sensitivity in various species. Adrenergic stimulation via the introduction of amphetamine leads to reliable increases in the aversive threshold to electric footshock in the rat (Houser \& Van Hart, 1973b), while reduced adrenergic tone produced by the administration of a $\alpha$-methyl-p-tyrosine ( $\alpha$-MT) has been reported to substantially raise the aversive threshold to electric shock in both the rat (Houser \& Van Hart, 1973b) and monkey (Houser \& Houser, 1973). Thus, both stimulation and depletion of adrenergic systems can lead to reliable increases in the aversive threshold to electric shock. Interpretation of the above results, however, is complicated by the fact that both agents substantially affect motor activity at most doses that alter the aversive threshold. Thus, $\alpha$-MT reduced motor activity in both the monkey (Houser \& Houser, 1973) and rat (Houser \& Van Hart, 1973b), while amphetamine produced the opposite effect by increasing activity. Since the aversive threshold is determined by an animal's motor response to various shock intensities, it is possible that the changes in the aversive threshold in response to these adrenergic drugs may have been the indirect result of changes in motor activity.

The present study was an attempt to explore the effects of several other adrenergic drugs to see if they also elevate the aversive threshold to electric shock. These agents included: reserpine, a drug which has been reported to deplete endogenous stores of both serotonin and the catecholamines in the brain (Nickerson, 1965);

The authors wish to express their appreciation to Mrs. Dale A. Van Hart for her assistance in preparing this manuscript. Thanks are also due to Mr. Richard L. Seiser for the excellent technical assistance he rendered during the execution of this study. The photographic work was done by Mr. Luther R. Gilliam, Chief of the Medical Illustration Service, VA Hospital, Perry Point, Maryland. phenoxybenzamine, an $\alpha$-adrenergic blocking agent; and propranolol, a $\beta$-adrenergic blocking agent. If adrenergic systems are involved in pain sensitivity, some or all of these drugs should affect the aversive threshold to electric shock. Furthermore, if changes in motor activity are, in fact, the underlying cause of the alterations in the aversive threshold, one would expect a high correlation between alterations in the aversive threshold and motor activity.

The present study investigated the effects of these three drugs upon the aversive threshold to electric shock as measured by the spatial preference technique in rats. This technique was first introduced by Campbell (1956). Our laboratory has modified Campbell's procedure so that repeated measures may be taken on individual animals. Previous reports have indicated that this modified technique is an extremely reliable and sensitive measure of drug-induced analgesia produced by a wide variety of analgesic agents known to be clinically active in man. For example, the technique is sensitive to a number of narcotic analgesics [i.e., morphine (Houser \& Paré, 1972), codeine, and meperidine hydrochloride (Houser \& Paré, 1973a)], weak analgesics [i.e., sodium salicylate, and indomethacin (Houser \& Paré, 1973b)], as well as the narcotic antagonist analgesics [i.e., pentazocine, and cyclazocine (Houser \& Paré, 1973a)]. The procedure also appears to be somewhat selective in that drugs that are clinically nonanalgesic in man are also inactive in the spatial preference technique. These results thus suggest that the spatial preference technique may be a more sensitive measure of drug-induced analgesia than previous analgesic assays. By utilizing this technique, the present report may supply more definitive information as to whether drugs which reduce adrenergic tone are able to affect the aversive threshold in rats. 


\section{METHOD}

\section{Subjects}

Eighteen male Sprague-Dawley-derived rats from ARS/Sprague-Dawley, Madison, Wisconsin, were used in the present study. They weighed $182-219 \mathrm{~g}$ at the beginning of the experiment.

\section{Apparatus}

The test chamber and procedure have been described in detail elsewhere (Houser \& Paré, 1972). Briefly, the chamber consisted of a rectangular Plexiglas shuttlebox which was pivoted in the middle, allowing the box to tilt from side to side as the animal crossed from one end to the other. This tilting movement activated a light-action Acro lever switch located at one end of the cage, which controlled the presentation of shock. The stainless steel rods which formed the floor of the cage could be electrified by various intensities of shock (i.e., 30, 60, 90, 120 , 150 microA). The shock stimulus was provided by a dc generator which produced a $60-\mathrm{Hz}$-square wave output. This unit was designed specifically to provide a constant current across an animal even when resistance was altered radically due to movements of the animal subjects (Reus, Houser, \& Paré, 1971). Standard electromechanical scheduling and recording equipment was located in an adjacent room. It was used to present the various shock intensities aut omatically and to record the amount of time in seconds spent on the shock side of the cage for each intensity, as well as the number of crossing responses made during each shock intensity of the daily sessions.

\section{Procedure}

Each animal was subjected to a 50-min experimental session, the same time each day, 6 days a week. An experimental session consists of five 10-min periods in which five separate current intensities (i.e., 30, 60, 90, 120, 150 microA) were presented in an ascending order. The shock was presented on one side of the cage for $5 \mathrm{~min}$ and then switched to the other side for the remaining $5 \mathrm{~min}$ of each current intensity. The animal could escape the shock side of the cage by merely crossing to the opposite or nonshock portion of the tilt cage. The shock was automatically switched from one side to the other every $5 \mathrm{~min}$ to insure that each animal sampled all shock intensities even if it failed to make a crossing response during the $10-\mathrm{min}$ period that each intensity was presented. Each animal was treated at all five shock intensities every day. In order to control for possible position preference, the initial shock presentation on a particular day was alternated from one side to another in a random fashion.

The dependent measure consisted of the amount of time in seconds spent on the shock side of the cage for each shock intensity. The aversive threshold was calculated daily for each animal by determining the intensity of shock which an animal avoided $75 \%$ of the time. At subthreshold intensities, the animal, by chance, would spend $50 \%$ of the time on the shock side of the cage. Since time spent on the shock side diminished as the shock intensity increased, the $75 \%$ threshold criteria required a simple interpolation process. If animals spent more than $25 \%$ of the available time on the shock side at the highest intensity (i.e., 150 microA), as was the case under some drug conditions, an aversive threshold could not be interpolated since no higher levels were presented. In these cases, a threshold value of 150 microA was arbitrarily assigned. The number of crossing responses made during each shock intensity was also recorded for each animal.

After 10 sessions, all animals demonstrated stable threshold values. Animals were then randomly assigned to three separate six-animal drug groups. Each drug was given in several separate doses in an ascending weekly series. Saline was administered for the first 3 days of each weekly series, followed by 3 days of a particular drug dosage. Animals were not tested on the 7 th day of these weekly series.

The three drugs administered in the present study consisted of reserpine (Serpasil, .62, 1.25, $2.50 \mathrm{mg} / \mathrm{kg}$ ), phenoxybenzamine hydrochloride (Dibenzyline, 5.0, 10.0, $20.0 \mathrm{mg} / \mathrm{kg}$ ), and propranolol (Inderal, 1.0, 2.0, 3.0, 4.0, 6.0, $8.0 \mathrm{mg} / \mathrm{kg}$ ). Reserpine was administered in the standard vehicle supplied with the 5-mg ampules of Serpasil from CIBA Pharmaceutical Company. The two lower dosages were prepared by diluting this drug-vehicle solution with $.9 \%$ saline. Both phenoxybenzamine and propranolol were dissolved in $.9 \%$ saline. All drugs were administered intraperitoneally (IP) in a volume of $1 \mathrm{ml} / \mathrm{kg}$. Since the major physiological effects of reserpine (i.e., depletion of endogenous catecholamines) occurs many hours after administration (Nickerson, 1965), this drug was administered $23 \mathrm{~h}$ before testing. Phenoxybenzamine and propranolol were given $1 / 2 \mathrm{~h}$ before threshold testing.

\section{RESULTS}

Figure 1 presents the mean aversive thresholds in microamperes and mean number of crossings recorded for the six animals subjected to various doses of reserpine. A two-factor within analysis of variance (Myers, 1966) performed on these data indicated that
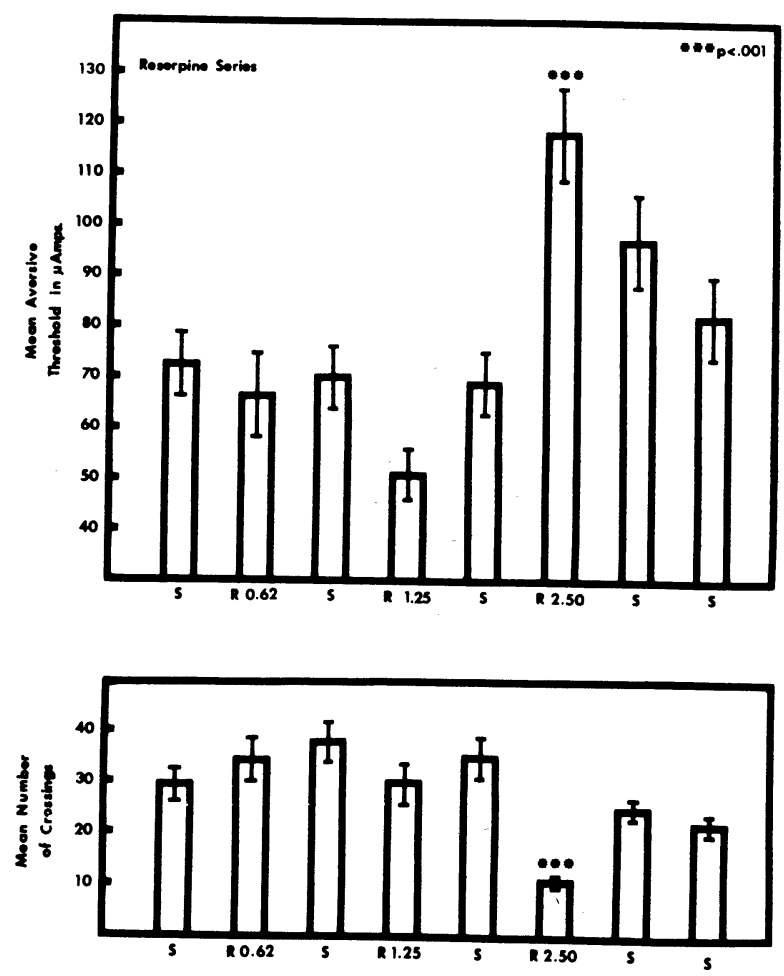

Figure 1. Mean aversive threshold and mean number of crossings with corresponding standard error of the means for those animals subjected to various doses of reserpine. Each bar represents the mean of three consecutive drug or saline (S) sessions. All drug dosages are given in $\mathrm{mg} / \mathrm{kg}$. Probability levels refer to statistical comparisons made between consecutive saline (S) and drug sessions. 
only the highest dose (i.e., $2.5 \mathrm{mg} / \mathrm{kg}$ ) of reserpine was able to increase the aversive threshold reliably. In addition, this particular dosage was the only one that significantly reduced the number of crossings recorded during the 50-min sessions. Thus, the increase in the aversive threshold noted under reserpine was correlated with reduced motor activity. The $2.5 \mathrm{mg} / \mathrm{kg}$ dosage of the drug also demonstrated toxic effects in that animals appeared lethargic. During the last six saline sessions, animals demonstrated reduced food intake and lost weight. Two of the six reserpine animals died 7 days after the last injection of $2.5 \mathrm{mg} / \mathrm{kg}$.

Figure 2 presents the mean aversive thresholds and mean number of crossings recorded for the six animals which were administered various dosages of phenoxybenzamine. A two-factor within analysis of variance (Myers, 1966) indicated that none of the dosages of this $\alpha$-adrenergic blocking agent tested reliably affected the aversive threshold. A similar analysis was performed on the crossing data which indicated that the two highest doses (i.e., 10.0, $20.0 \mathrm{mg} / \mathrm{kg}$ ) reliably reduced motor activity. In addition, the highest dose produced visible signs of sedation. Six days after the highest dose was withdrawn, two of the six animals died.

Finally, Figure 3 presents the mean aversive thresholds and mean number of crossings for the six animals subjected to various doses of the $\beta$-adrenergic
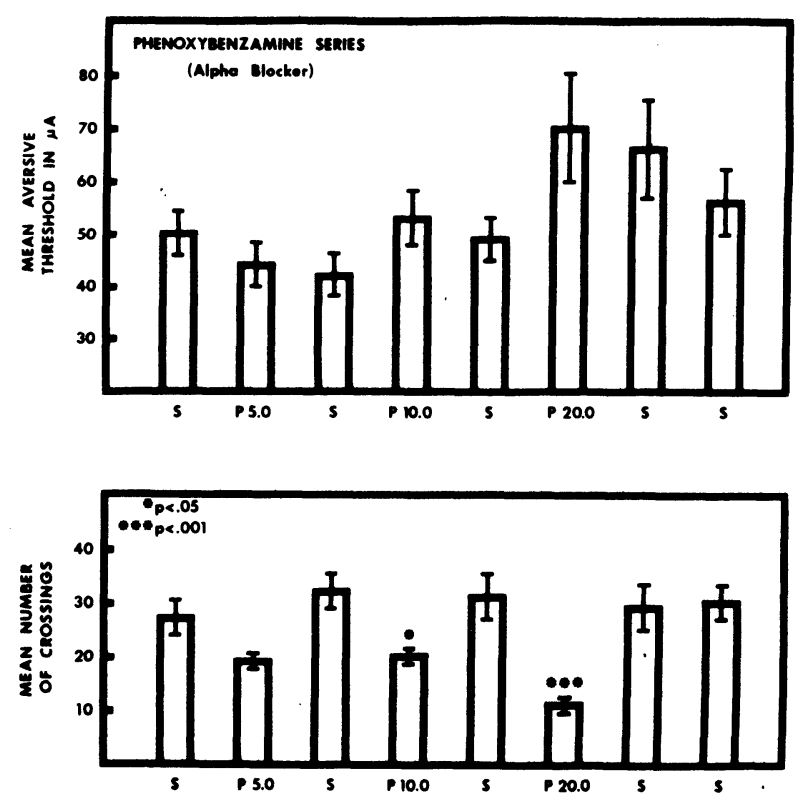

Figure 2. Mean aversive threshold and mean number of crossings with corresponding standard error of the means for those animals subjected to various doses of phenoxybenzamine. Each bar represents the mean of three consecutive drug or saline (S) sessions. All drug dosages are given in $\mathrm{mg} / \mathrm{kg}$. Probability levels refer to statistical comparisons made between consecutive saline (S) and drug sessions.
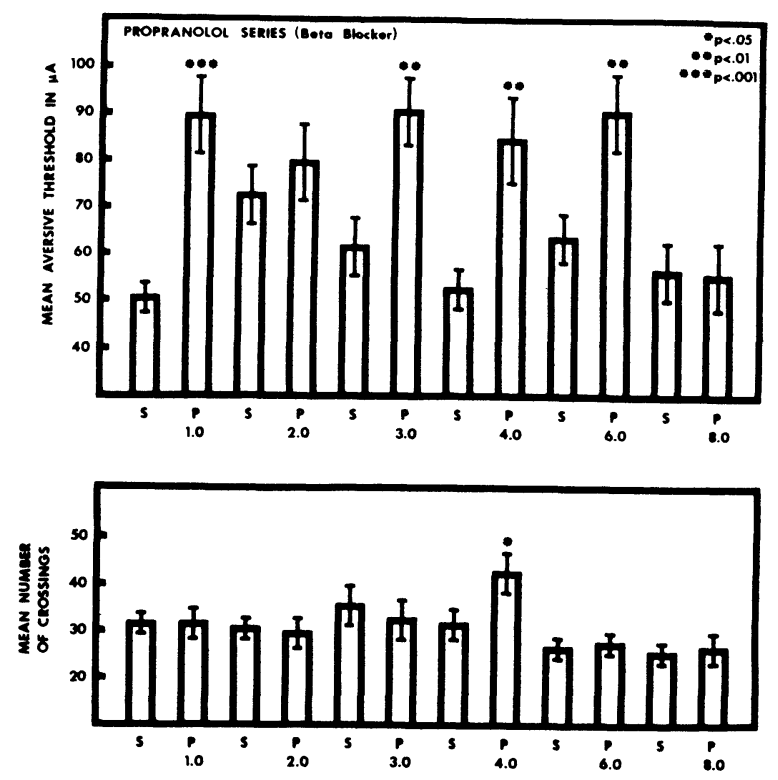

Figure 3. Mean aversive threshold and mean number of crossings with corresponding standard error of the means for those animals subjected to various doses of propranolol. Each bar represents the mean of three consecutive drug or saline (S) sessions. All drug dosages are given in $\mathrm{mg} / \mathrm{kg}$. Probability levels refer to statistical comparisons made between consecutive saline (S) and drug sessions.

blocking agent, propranolol. Again, a two-factor within analysis of variance (Myers, 1966) indicated that all dosages, with the exception of the 2.0 and $8.0 \mathrm{mg} / \mathrm{kg}$ series, reliably elevated the aversive threshold. These elevations, however, were not dose related in that the lowest dosage (i.e., $1.0 \mathrm{mg} / \mathrm{kg}$ ) produced effects similar in degree to higher doses. An analysis of the crossing data indicated that only the $4.0 \mathrm{mg} / \mathrm{kg}$ dosage reliably affected motor activity by producing an elevation in the number of locomotor crossing responses made during the 50-min sessions. No visible signs of toxicity were noted in these animals and none died after drug treatment.

\section{DISCUSSION}

The present results indicate that only the $\beta$-adrenergic blocking agent, propranolol, consistently elevated the aversive threshold over a wide range of doses without affecting motor activity. Reserpine augmented the aversive threshold only under the highest dose tested, while phenoxybenzamine produced no consistent effects on pain sensitivity.

Although very little evidence exists with regard to the analgesic or antianalgesic effects of reserpine, studies have been carried out which explored the effects of reserpine on morphine-induced analgesia. Dewey, Harris, Howes, and Nuite (1970) have reported that 
pretreatment with reserpine $16 \mathrm{~h}$ before morphine administration reduced the analgesic effects of this narcotic in the mouse tail-flick test. If reserpine is given simultaneously with morphine, however, it acts to enhance narcotic-induced analgesia as measured in the mouse tail-flick test (Dewey et al., 1970). These results have been interpreted to suggest that adrenergic stimulation caused by the release of endogenous catecholamines immediately after the administration of reserpine leads to enhanced morphine analgesia. A reduction in adrenergic tone, however, caused by depletion of the catecholamines several hours after treatment with reserpine antagonizes morphine's analgesic effects (Dewey et al., 1970). In agreement with this analysis, Grossman, Jurna, Nell, and Theres (1973) have reported that $75 \mathrm{~min}$ after reserpine administration, rats demonstrated an analgesic response in the tail-flick test. Thus, reserpine by itself can produce an analgesic response immediately after its administration in the rat.

The present results extend the above findings by suggesting that reserpine given alone can lower the mean aversive threshold to some degree (i.e., Figure 1, .62 and $1.25 \mathrm{mg} / \mathrm{kg}$ dosages) $23 \mathrm{~h}$ after administration of the drug. The fact that these mean reductions were not statistically significant may suggest that testing should occur somewhat earlier (i.e., $12-16 \mathrm{~h}$ after drug treatment) when depletion of endogenous stores of the catecholamines may be greater. It is more likely that the effects of reserpine on the aversive threshold were caused by its effects on catecholamine rather than serotonin levels, since earlier work in this laboratory (Houser \& Van Hart, 1974) has indicated that p-chlorophenylalanine, a serotonin-depleting agent, had no reliable effects on the aversive threshold. The fact that the highest dose (i.e., $2.5 \mathrm{mg} / \mathrm{kg}$ ) of reserpine produced significant elevations in the aversive threshold $23 \mathrm{~h}$ after drug administration probably represents the toxic effects of this high dosage. This conclusion is supported by the reduction in motor activity noted under this dosage, the general appearance of the animals, and the fact that two of the six animals died during the week following drug administration. It would thus appear that reserpine elevates the aversive threshold several hours after drug treatment only if toxic doses are administered and may, in fact, lower the threshold if animals are tested at a point in time when catecholamine stores are maximally depleted.

Very little direct evidence exists with regard to the effects of $\alpha$-adrenergic blocking agents upon pain sensitivity. The present results indicate that the aversive threshold was statistically unaltered by any of the dosages tested. Even the highest dose (i.e., $20.0 \mathrm{mg} / \mathrm{kg}$ ) which appeared toxic did not significantly affect the threshold although motor activity was severely reduced. Thus, it would appear that the $\alpha$-adrenergic blocking agent, phenoxybenzamine, does not reliably affect the aversive threshold of the rat to electric shock even when administered at toxic doses.

The only agent in the present study to consistently alter the aversive threshold was the $\beta$-adrenergic blocking agent, propranoiol. This effect was not dose related, nor did any of the dosages produce maximum aversive thresholds (i.e., 150 microA). Furthermore, these effects did not appear to be the result of a change in motor activity or drug-induced toxicity. These findings suggest that this $\beta$-adrenergic blocking agent may have produced a mild analgesic effect at least in dosages at or below $6.0 \mathrm{mg} / \mathrm{kg}$. Other reports in the literature have indicated that propranolol may have some analgesic properties. Dewey et al. (1970) have noted that $100 \mathrm{mg} / \mathrm{kg}$ of propranolol in mice has some analgesic potency in the tail-flick test. Furthermore, propranolol has been reported to display potent local anesthetic properties and has been used for ocular anesthesia (Singh, Kulshrestha, Mahawar, Gautam, \& Singh, 1967). In addition, Morales-Aguilera and Vaughan Williams (1965) have reported that propranolol was found to be 2.3 times more potent than procaine as a local anesthetic in guinea pigs. It is possible, therefore, that the intraperitoneal administration of propranolol in relatively high doses may produce mild analgesia to electric footshock in the rat via the drug's local anesthetic properties.

In summary, the data contained in the present report strongly suggest that reductions in adrenergic tone do not lead to significant dose-related elevations in the aversive threshold. The changes that do occur can be accounted for in terms of the toxic effects of the drugs employed or to their local anesthetic properties. The reduction of central adrenergic tone, either by reserpine as in the present report, or by $\alpha$-methyl-p-tyrosine (Houser \& Van Hart, 1973a) does lead to significant elevations in the aversive threshold, but only when high doses that usually produce severe decrements in motor activity are administered. It would thus appear that reductions in central adrenergic tone do not directly augment the aversive threshold. The elevations that are noted probably reflect the debilitating motor effects produced when high drug dosages are administered.

\section{REFERENCES}

Campbell, B. A. The reinforcement difference limen (RDL) function for shock reduction. Journal of Experimental Psychology, 1956, 52, 268-272.

Dewey, W. L., Harris, L. S., Howes, J. F., \& Nuite, J. The effect of various neurohumoral modulators on the activity of morphine and the narcotic antagonists in the tail-flick and phenylquinone tests. The Journal of Pharmacology and Experimental Therapeutics, 1970, 175, 435-442.

Grossman, W., Jurna, I., Nell, T., \& Theres, C. The dependence of the anti-nociceptive effect of morphine and other analgesic agents on spinal motor activity after central monoamine depletion. European Journal of Pharmacology, 1973, 24, 67-77.

Houser, V. P., \& Houser, F. L. The alteration of aversive thresholds with cholinergic and adrenergic agents. Pharmacology Biochemistry and Behavior, 1973, 1, 433-444.

Houser, V. P., \& Paré, W. P. A method for determining the aversive threshold in the rat using repeated measures: Tests 
with morphine sulfate. Behavior Research Methods \& Instrumentation, 1972, 4, 135-137.

Houser, V. P., \& Paré, W. P. Measurement of analgesia using spatial preference test in the rat. Physiology and Behavior, 1973a, 10, 535-538.

Houser, V. P., \& Paré, W. P. Analgesic potency of sodium salicylate, indomethacin, and chlordiazepoxide as measured by the spatial preference technique in the rat. Psychopharmacologia, 1973b, 32, 121-131.

Houser, V. P. \& Van Hart, D. A. The effects of scopolamine and pilocarpine upon the aversive threshold of the rat. Pharmacology Biochemistry and Behavior, 1973a, 1, 427-431.

Houser, V. P., \& Van Hart, D. A. Changes in the aversive threshold of the rat produced by adrenergic drugs. Pharmacology Biochemistry and Behavior, 1973b, 1, 673-678.

Houser, V. P., \& Van Hart, D. A. Serotonin and the aversive threshold in rats. Bulletin of the Psychonomic Society, 1974, 3, 388-390.

Morales-Aguilera, A., \& Vaughan Williams, E. M. The effects on cardiac muscle of $\beta$-receptor antagonists in relation to their activity as local anaesthetics. British Journal of Pharmacology, $1965,24,332-338$.

Myers, J. Fundamentals of experimental design. Boston: Allyn \& Bacon, 1966. Pp. 170-171.

Nickerson, M. Drugs inhibiting adrenergic nerves and structures innervated by them. In L. Goodman and A. Gilman (Eds.), The pharmacological basis of therapeutics. New York: MacMillan, 1965. P. 569 .

Reus, J. F., Houser, V. P., \& Paré, W. P. An electronic constant current shock generator for low current levels. Physiology and Behavior, 1971, 7, 635-637.

Singh, K. P., Kulshrestha, O. P., Mahawar, M. M., Gautam, S. K., \& Singh, M. M. Propranolol for ocular anaesthesia. Lancet, $1967,2,158$.

(Received for publication September 10, 1974; revision received October 11,1974 .) 